\title{
THE SYSTEMATIC APPROACH AND LEGAL FORMS TO ENSURE ROAD SAFETY IN RUSSIA
}

\author{
Gennady G. Egorov \\ Volzhsky Branch of Volgograd State University, Volzhsky, Russian Federation
}

\begin{abstract}
Introduction: the constant growth of offenses on the roads, among other factors, is due to the imperfection of the statutory regulation, and the lack of systematic interpretation of the scientific problems in this area. The purpose of the work is to identify the main legal components of road safety and the rationale for the consistency need in the definition of the fundamental forms of road safety. Using the methods of scientific knowledge, first of all, the method of system analysis, it is found that the complexity of the problem involves the use of both lawmaking and enforcement "vision" of the main directions and forms of preventing traffic safety violations. Results: the noted shortcomings of the development of norm-setting were identified on the basis of the analysis of the electronic banks data, which allowed justifying the need for organizational measures to improve the rules of law and law enforcement in the country and proposing a number of corrective measures. Conclusions: 1) to establish a system of civil monitoring of the behavior legality on the roads both within the country and Southern Federal District; 2) to introduce the uniform forms of improving the analysis of the authorities' efficiency in the fight against such offenses; 3 ) to approve at the federal level the main measures to reduce the level of injuries on the roads.

Key words: offense, safety, liability, traffic rules, system approach, factors of antisocial behavior on the roads, good behavior, administrative law.
\end{abstract}

Citation. Egorov G.G. The Systematic Approach and Legal Forms to Ensure Road Safety in Russia. Legal Concept, 2018, vol. 17, no. 3, pp. 28-34. DOI: https://doi.org/10.15688/lc.jvolsu.2018.3.4

УДК $351 / 74$

ББК 67.401.133.12

\section{СИСТЕМНЫЙ ПОДХОД И ЮРИДИЧЕСКИЕ ФОРМЫ ОБЕСПЕЧЕНИЯ БЕЗОПАСНОСТИ ДОРОЖНОГО ДВИЖЕНИЯ В РОССИИ}

\author{
Геннадий Геннадьевич Егоров
}

Волжский филиал Волгоградского государственного университета, г. Волжский, Российская Федерация

Введение: постоянный рост правонарушений на дорогах, помимо других факторов, обусловливается несовершенством нормативного регулирования, недостатками системности интерпретации научных проблем этой сферы. Целью работы является выделение основных юридических составляющих обеспечения безопасности дорожного движения и обоснование необходимости системности в определении основополагающих форм обеспечения безопасности дорожного движения. С помощью методов научного познания, прежде всего метода системного анализа, установлено, что сложность выделенной проблемы предполагает использование как правотворческого, так и правореализационного «виденья» основных направлений и форм предотвращения нарушений правил безопасности дорожного движения. Результаты: отмеченные недостатки развития нормотворчества выявлены на основе анализа данных электронных банков, позволившего обосновать необходимость организационных мероприятий по совершенствованию норм права и правоприменительной практики в стране и предложить ряд мер по их устранению. Выводы: необходимо 1) создание системы гражданского мониторинга правомерности поведения на дорогах как в рамках страны, так и Южного федерального округа; 2) введение единообраз3) утверждение на федеральном уровне основных мероприятий по снижению уровня травматизма на дорогах среди детей и др. 
Ключевые слова: правонарушения, безопасность, ответственность, правила дорожного движения, системный подход, факторы асоциального поведения на дорогах, правомерное поведение, административное право.

Цитирование. Егоров Г. Г. Системный подход и юридические формы обеспечения безопасности дорожного движения в России // Legal Concept = Правовая парадигма. - 2018. - T. 17, № 3. - C. 28-34. - DOI: https://doi.org/10.15688/lc.jvolsu.2018.3.4

\section{Введение}

В России за прошедшее десятилетие в дорожно-транспортных происшествиях погибли около 350 тысяч человек, еще более 3 миллионов травмированы, заявил президент Владимир Путин на заседании президиума Госсовета в Ярославле 14 марта 2016 года. Президент назвал эти потери страшными, бессмысленными жертвами, которых можно было избежать [5].

В процессе использования достижений технического прогресса человек сталкивается с необходимостью государственного контроля допустимых пределов применения таких средств. Автотранспортное средство, как источник повышенной опасности, является классическим примером объектов повышенного внимания власти. Следует помнить, что безопасность дорожного движения представляет собой состояние защищенности участников дорожного движения от рисков возникновения ДТП и их последствий. Но какова допустимая степень безопасности, пределы безопасности, где границы приемлемых рисков с учетом того, что аварийность и количество пострадавших в результате дорожно-транспортных происшествий невозможно свести к нулю? Частично ответы на обозначенные вопросы находят свое выражение в Федеральной целевой программе «Повышение безопасности дорожного движения в 2013-2020 годах», в которой указаны цели и задачи, направления реализации [6].

Обеспечение безопасности дорожного движения - задача системная и, безусловно, требует подхода, позволяющего выявлять недостатки в нормативно-правовой регламентации действующей совокупности обеспечения безопасности на дорогах, формировать организационно-правовые мероприятия органов власти по снижению неправомерного поведения на дорогах.

\section{Теоретические аспекты обеспечения безопасности дорожного движения}

Представители отечественной науки разрабатывают содержание понятий, выделяют особенности и отличительные признаки правовых категорий в этой сфере. Содержание элементов, характеризующих признаки исследуемых понятий, трансформировалось с учетом совершенствования нормативных правовых актов, регламентирующих общественные отношения в этой области, а также с учетом развития научных представлений. Базовое исследование, определяющее понятие системного подхода при решении задач по борьбе с правонарушениями, было проведено в 1996 г. Ю.И. Мироновым [8]. При этом исследователи безопасности дорожного движения указывают на существование методологических трудностей, связанных с определением пределов соотнесения содержательной части исследуемого процесса (то есть структура и функция, подлежащие защите) и аспектов, связанных с комплексом методов и средств обеспечения их безопасности [2].

Рассматривая практические аспекты обеспечения безопасности на дорогах, нельзя не отметить значительную роль органов власти всех уровней, профильных ведомств, хозяйствующих субъектов по ее обеспечению, при этом системообразующей формой, юридически обеспечивающей безопасность эксплуатации всех видов транспорта, является законодательство.

Так, по данным на осень 2016 г, федеральное законодательство, напрямую затрагивающее безопасность дорожного движения, представлено более чем 400 актами; в то же время региональные нормы (на примере Волгоградской области), не отставая от федерального регламентирования, представлены порядка 300 актами. При этом сейчас на рассмотрении находится более 450 законопроектов ${ }^{1}$. 
В 2015 г. для снижение смертности на дорогах по поручению президента должны были быть приняты меры, а Правительство утвердило соответствующий план мероприятий, в котором было намечено внести в Государственную Думу 13 законопроектов, однако все сроки были нарушены. Из этого числа лишь один законопроект поступил в Госдуму, а остальные проходили согласование в Правительстве [6]. Президентом также поставлена задача законодательного регулирования вопросов транспортного разделения территорий с учетом организации безопасного движения и оперативного управления.

Проведенные системные исследования выделенной сферы нормативно-правового регулирования обеспечения безопасности на дорогах позволяют нам выявить наиболее характерные недостатки. В их числе:

- неполная мера регулирования общественных отношений в данной области, содержание целого ряда противоречий;

- наличие пробелов в нормативном правовом регулировании координационных форм деятельности представителей органов исполнительной власти на всех уровнях функционирования;

- недостаточно конкретное регламентирование порядка финансирования необходимых мероприятий;

- неконкретность и неполнота регламентации форм и методов контроля за соблюдением требований безопасности дорожного движения;

- отсутствие норм, стимулирующих участие как представителей гражданского общества, так и средств массовой информации в сфере предупреждения аварийности.

Можно также сделать вывод, что законодательство в данной области не в состоянии обеспечить в полной мере реализацию основной задачи - предупреждения неправомерных действий.

\section{Нормативно-правовые аспекты обеспечения безопасности в сфере дорожного движения}

Действующее законодательство не в полной мере соответствует возросшим общественным потребностям, а также международно- правовым стандартам. В этой связи перед институтами теории и практики государственного управления встали серьезные сложности, устранение которых возможно только с учетом критического анализа соответствующих норм национального и зарубежного законодательства, но главное при этом - разработка и реализация научно обоснованной и практически апробированной концепции системы обеспечения безопасности на дорогах в РФ.

Заметим: в стране с 1995 г. действует Ф3 «О безопасности дорожного движения» [12]. В Законе используется понятие «проведение государственной политики в области обеспечения безопасности дорожного движения», но ни в данном Законе, ни в иных нормах права не раскрыты формы реализации данной политики. Также не определяются вопросы разграничения компетенций между федеральной властью, органами власти субъектов Российской Федерации, а также представителями органов местного самоуправления [9].

Данный подход был неоднократно апробирован в территориальных условиях. Наиболее показательным является деятельность ГИБДД г. Москвы. Так, мэр С. Собянин в 2012 г. определил необходимость принятия комплекса мер, ориентированных на скорейшее оздоровление ситуации. При этом данный проект планирует значительное увеличение числа оборудованных парковочных мест, формируемых посредством более эффективного применения придомовых территорий; строительство перехватывающих парковок рядом с периферийными станциями московского метрополитена, призванных разгрузить основные магистрали города от гражданского автотранспорта; создание новых станций московского метрополитена (выходящих за пределы границ г. Москва); выделение дополнительных полос для общественного транспорта в рамках уже существующих магистральных трасс; а также необходимость тесного взаимодействия с руководством Московской области в сфере устранения транспортных дефектов и решения вопроса о сокращении числа съездов/выездов на МКАД в связи со значительным числом торговых центров в непосредственной близи от данной автодороги [1].

Следует отметить, что в соответствии с законодательством о безопасности дорож- 
ного движения все формы проектирования, строительства и реконструкции дорог в России должны преследовать цель обеспечения безопасность дорожного движения. Необходимость соответствия построенных, а также реконструированных дорог требованиям технической регламентации и иным нормам определяется заключением специально уполномоченным на осуществление государственного надзора в сфере строительства федеральным органом исполнительной власти или уполномоченным на осуществление государственного надзора в данной сфере органом исполнительной власти субъекта РФ в соответствии с предписаниями законодательства страны в градостроительной сфере деятельности.

Соответствие дорог установленным требованиям безопасности обеспечивается через определение норм ответственности еще на этапах проектирования у исполнителей проекта, a на этапах реконструирования и строительства - уже у исполнителей работ. При этом проектирование, строительство и реконструкция дорог не допускает снижение капитальных затрат за счет инженерных решений, имеющих отрицательное влияние на обеспечение безопасности дорожного движения.

Федеральная целевая программа «Повышение безопасности дорожного движения в 2013-2020 годах» для наиболее эффективного решения данных проблем, а также дальнейшего уменьшение показателей аварийности до уровня развитых стран мира предполагает необходимым продолжать системные меры по реализации всевозможных мер, направленных на повышение безопасности дорожного движения, а также по обеспечению их финансовыми ресурсами, что требует продолжения развития институтов обеспечения реализации комплекса мер по повышению уровня безопасности на дорогах.

Эффективность в продолжении решения проблемы возможна только в условиях длящегося применения в качестве основополагающего программно-целевого метода, принятого и впоследующем реализуемого через программы различного уровня [11].

Таким образом, применение программноцелевых методов для решения текущих проблем в сфере безопасности дорожно-транспортной системы страны позволило сохранить на- копленный потенциал и фактически сократить число погибших в ДТП по Российской Федерации, гармонизировать систему обеспечения безопасности дорожного движения и определило предпосылки достижения более значимых стратегических целей по снижению дорожнотранспортного травматизма на последующее десятилетие. Также следует отметить, что для достижения данных целей в России принят закон, ужесточающий ответственность за агрессивное поведение на дорогах.

Следует отметить, что реализация запланированных мероприятий Программы поможет сопровождать возникающие следующие законодательные, информационные, кадровые и иные негативные факторы:

- пробелы и противоречия в правовой базе, ограничивающие основные формы действий и взаимодействий органов государственной власти, а также способность эффективного реагирования на ситуации, связанные с безопасностью на дорогах;

- недостатки, а иногда и отсутствие сведений о целях, направлениях и результатах деятельности в сфере обеспечения безопасности дорожного движения;

- ненадлежащая пропаганда безопасности на дорогах, а также культуры поведения основных участников движения.

Снижения факторов негативного влияния на реализацию Программы требует создания и поддержания в актуальном состоянии всех процессов, связанных с планированием, исполнением, мониторингом, контролем и ресурсным обеспечением данной программной деятельности, а равно межведомственного и межуровневого взаимодействия по обеспечению публичности, информационной открытости и основных показателей инвестиционной привлекательности [4].

Для достижения целей необходимо продолжать профилактическую и воспитательную работу с населением, и в первую очередь - с подрастающим поколением. Необходимо, как и раньше, вести работу по пропаганде безопасности дорожного движения с использованием игровых ситуаций и интерактивных методов обучения в дошкольных учебных заведениях и общеобразовательных школах. Необходимо активизировать способы пропаганды безопасности дорожного движения, 
включая создание специальных телепрограмм, посвященных анализу произошедших аварий. Для поддержания в эстетическом виде транспорта необходимо проводить месячники «Чистое авто» [10].

\section{Выводы}

Следует принять надлежащие меры для реализации предусмотренных в Приложении № 7 к Федеральной целевой программе «Повышение безопасности дорожного движения в 2013-2020 годах» цикла мероприятий, направленных на снижение организационно-правовых предпосылок возникновение угроз такой безопасности:

- разработка и внедрение механизма по установлению индивидуальных целевых заданий для субъектов РФ, направленных на снижение уровня дорожно-транспортной аварийности на период вплоть до 2020 г., и введение субсидиарной ответственности как федерального центра, так и субъектов Федерации за нарушение реализации поставленных целей и задач;

- определение текущего положения, а также форм построения научно обоснованных моделей по разграничению полномочий (сфер ответственности) между органами исполнительной власти различного уровня, в том числе органов местного самоуправления;

- внедрение комплекса научно-практических разработок, направленных на определение основополагающих исследовательских методов по поддержанию принятых решений и управлению в сфере безопасности дорожного движения с учетом особенностей федерального, регионального и местного уровней, а также формирование механизмов комплексной оценки эффективности и результативности текущих программных продуктов;

- разработка наиболее перспективных форм привлечения внебюджетных средств в наиболее приоритетные проекты, связанные с обеспечением безопасности на дорогах, а также развитие государственного и частного партнерства, создание эффективных саморегулируемых организаций и наиболее привлекательных методов аутсорсинга в сфере обеспечения безопасности на дорогах;

- проведение научно-практических исследований в области использования ЭВМ- продуктов, осуществляющих математическое моделирование транспортных потоков при создании комплексных схем по организации наиболее значимых разновидностей дорожного движения, а также проектов машинно-логических систем по управлению дорожным движением; роботизация дорожного движения; разработка данных предложений в рамках нормативного и методического обеспечения по использованию указанных систем в области проектирования сферы организации дорожного движения.

\section{Заключение}

По своему содержанию все мероприятия затрагивают экономические, технические, правовые, организационные, медицинские, психологические, кибернетические и другие проблемы.

Ряд ученых предлагают использовать комплекс специальных мер обеспечения производства по делам об административных правонарушениях в области дорожного движения, обосновывая это необходимостью комплексной оценки данных проблем [3].

Следует отметить: высокая степень динамики развития в мире угроз безопасности как общего, так и специального характера формирует юридические предпосылки закрепления за военными организациями обособленного положения, характеризующегося высокой степенью ответственности за предотвращение угроз любого вида для современного общества. Исключительная важность таких задач, как отражение агрессии, направленной против Российской Федерации, вооруженная защита целостности и неприкосновенности территории Российской Федерации, не вызывает сомнений. В таких условиях должна быть обеспечена всесторонняя поддержка деятельности военных организаций, в том числе с помощью адекватной правовой регламентации определенных сфер правоотношений с их участием. В частности, было бы целесообразным урегулировать положение участников ДТП, произошедшего в зоне ведения боевых действий, с помощью специального нормативного правового акта, например, освободив участников ДТП от указанных выше обязанностей и предусмотрев специальный по- 
рядок возмещения причиненного в этом случае вреда [7].

Подводя итог обзора научно-практических проблем обеспечения безопасности дорожного движения, можно отметить преобладание в большей степени работ, затрагивающих теоретические вопросы исполнения действующего законодательства, и значительно меньший объем исследований, проводимых непосредственными представителями власти. Такая ситуация, на наш взгляд, снижает эффективность научных исследований в данной области, хотя и не исключает положительного результата.

На сегодняшний день для изучения многих видов человеческой деятельности требуются систематические наблюдения и подробное документирование с целью анализа полученных данных, прогнозирования развития благоприятных ситуаций или негативных последствий.

\section{ПРИМЕЧАНИЕ}

1 По результатам анализа СПКС «КонсультантПлюс: Региональноезаконодательство» на 20.102016 г.

\section{СПИСОК ЛИТЕРАТУРЫ}

1. Войтенков, Е.А. Комплексный анализ деятельности государственных и муниципальных органов власти по улучшению транспортной ситуации и безопасности дорожного движения в городе Москве / Е. А. Войтенков // Государственная власть и местное самоуправление. - 2012. - № 3. - С. 41-42.

2. Головко, В. В. К вопросу о понятии безопасности дорожного движения / В. В. Головко // Правопорядок: история, теория, практика. 2015. - № 1 (4). - С. 62-69.

3. Горяинов, А. И. Специальные меры обеспечения производства по делам об административных правонарушениях в области дорожного движения, применяемые в отношении водителей транспортных средств / А. И. Горяинов, В. В. Кузин, А. Ю. Якимов // Административное право и процесс. -2010 . - № 5. - С. 20-26.

4. Егоров, Г. Г. Особенности научно-правовой интерпретации проблем исполнения правовых норм в сфере обеспечения безопасности на дорогах Российской Федерации / Г. Г. Егоров // Философия социальных коммуникаций. - 2014. - № 4 (29). C. 55-63.
5. Заседание президиума Госсовета по вопросам безопасности дорожного движения [Выступление Президента В. Путина]. - Электрон. текстовые дан. - Ярославль, 14 марта 2016 г., 17.30. - Режим доступа: http://www.kremlin.ru/events/ president/news/51506. - Загл. с экрана.

6. Калюжный, Ю. Н. Отдельные теоретические подходы к толкованию понятия «безопасность дорожного движения» / Ю. Н. Калюжный // Транспортное право. - 2016. - № 2. - С. 3-7.

7. Миронов, Ю. И. Административное право : (учебно-методическое пособие) / Ю. И. Миронов, Г. Г. Егоров. - М. : МЮИ, 2011. - 300 с.

8. Миронов Ю. И. Системный подход в организации раскрытия преступлений : дис. ... канд. юрид. наук / Миронов Юрий Иванович. - Волгоград, 1996. - $184 \mathrm{c}$.

9. Орешкина, И. Б. Актуальные проблемы реализации правил дорожного движения в Российской Федерации (на примере Волгоградской области) : монография / И. Б. Орешкина, Г. Г. Егоров. Краснослободск : ИП Головченко Е. А., 2015. - 124 с.

10. Прибавина, Т. А. Пути решения основных проблем в области повышения безопасности дорожного движения / Т. А. Прибавина, Н. Н. Полесико // Транспортное право. - 2015. - № 4. - С. 11-13.

11. Распоряжение Правительства РФ от 27.10.2012 № 1995-р «Об угверждении Концепции федеральной целевой программы "Повышение безопасности дорожного движения в 2013-2020 годах”» // Собрание законодательства РФ. - 2012. - 5 нояб. (№ 45). - Ст. 6282.

12. Федеральный закон от 10.12.1995 № 196-Ф3 «О безопасности дорожного движения» : (ред. от 03.07.2016) : (с изм. и доп., вступ. в силу с 15.07.2016) // Российская газета. - 1995. - 26 дек. (№ 245).

\section{REFERENCES}

1. Voytenkov E.A. Kompleksnyy analiz deyatelnosti gosudarstvennykh i munitsipalnykh organov vlasti po uluchsheniyu transportnoy situatsii i bezopasnosti dorozhnogo dvizheniya $\mathrm{v}$ gorode Moskve [Comprehensive Analysis of the Activities of State and Municipal Authorities to Improve the Transport Situation and Road Safety in the City of Moscow]. Gosudarstvennaya vlast $i$ mestnoe samoupravlenie [State Power and Local SelfGovernment], 2012, no. 3, pp. 41-42.

2. Golovko V.V. K voprosu o ponyatii bezopasnosti dorozhnogo dvizheniya [On the Issue of the Concept of Traffic Safety]. Pravoporyadok: istoriya, teoriya, praktika, 2015, no. 1 (4), pp. 62-69.

3. Goryainov A.I., Kuzin V.V., Yakimov A.Yu. Spetsialnye mery obespecheniya proizvodstva po 
delam ob administrativnykh pravonarusheniyakh $\mathrm{v}$ oblasti dorozhnogo dvizheniya, primenyaemye $\mathrm{v}$ otnoshenii voditeley transportnykh sredstv [Special Measures to Ensure Administrative Proceedings in the Sphere of Road Traffic, Applied to Drivers of Vehicles]. Administrativnoe pravo i protsess, 2010, no. 5, pp. 20-26.

4. Egorov G.G. Osobennosti nauchno-pravovoy interpretatsii problem ispolneniya pravovykh norm v sfere obespecheniya bezopasnosti na dorogakh Rossiyskoy Federatsii [Scientific and Legal Interpretation of the Problems of Legal Norms Enforcement in the Sphere of Ensuring Safety on the Roads of the Russian Federation]. Filosofiya sotsialnykh kommunikatsiy [Philosophy of Social Communications], 2014, no. 4 (29), pp. 55-63.

5. Vystuplenie Prezidenta V. Putina na zasedanii prezidiuma Gossoveta po voprosam bezopasnosti dorozhnogo dvizheniya [Speech by President V. Putin at the Meeting of the State Council Presidium on Road Safety Issues]. Yaroslavl, 2016, March 14. URL: http://www.kremlin.ru/events/ president/news/51506.

6. Kalyuzhnyy Yu.N. Otdelnye teoreticheskie podkhody $\mathrm{k}$ tolkovaniyu ponyatiya «bezopasnost dorozhnogo dvizheniya» [Some Theoretical Approaches to the Interpretation of the Concept of 'road Safety']. Transportnoe pravo, 2016, no. 2, pp. 3-7.

7. Mironov Yu.I., Egorov G.G. Administrativnoe pravo [Administrative Law]. Moscow, MUI Publ., 2011. $300 \mathrm{p}$.

8. Mironov Yu.I. Sistemnyy podkhod v organizatsii raskrytiya prestupleniy: dis. ... kand. yurid. nauk [A Systematic Approach to Crime Detection. Cand. jurid. sci. diss.]. Volgograd, 1996. $184 \mathrm{p}$.

9. Oreshkina I.B., Egorov G.G. Aktualnye problemy realizatsii pravil dorozhnogo dvizheniya $v$ Rossiyskoy Federatsii (na primere Volgogradskoy oblasti) [Current Problems of the Implementation of Traffic Rules in the Russian Federation (the Case of the Volgograd Region)]. Krasnoslobodsk, IP Golovchenko Publ., 2015. 124 p.

10. Pribavina T.A., Polesiko N.N. Puti resheniya osnovnykh problem $\mathrm{V}$ oblasti povysheniya bezopasnosti dorozhnogo dvizheniya [The Ways to Solve the Main Problems in the Field of Improving Road Safety]. Transportnoe pravo, 2015, no. 4, pp. 11-13.

11. Rasporyazhenie Pravitelstva RF ot 27.10.2012 № 1995-r «Ob utverzhdenii Kontseptsii federalnoy tselevoy programmy "Povyshenie bezopasnosti dorozhnogo dvizheniya v 2013-2020 godakh"» [Decree of the Government of the Russian Federation of October 27, 2012 No. 1995-r 'On the Approval of the Conception of the Federal Target Program "Improving Road Safety in 2013-2020"']. Sobranie zakonodatelstva RF [Collected Legislation of the Russian Federation], 2012, no. 45, art. 6282.

12. Federalnyy zakon ot 10.12.1995 № 196-FZ «O bezopasnosti dorozhnogo dvizheniya» : (red. ot 03.07.2016) : (s izm. i dop., vstup. v silu s 15.07.2016) [Federal Law of 10 December 1995 No. 196-FZ 'On the Safety of Road Traffic' (ed. of 3 July 2016): (with amend. and add. of 15 July 2016)]. Rossiyskaya gazeta, 1995, no. 245 (December 26).

\section{Information about the Author}

Gennadiy G. Egorov, Candidate of Sciences (Jurisprudence), Associate Professor, Researcher, Department of Scientific and International Activities, Volzhsky Branch of Volgograd State University, 40 let Pobedy St., 11, 404133 Volzhsky, Russian Federation, egorov@vgi.volsu.ru.

\section{Информация об авторе}

Геннадий Геннадьевич Егоров, кандидат юридических наук, доцент, научный сотрудник отдела научной и международной деятельности, Волжский филиал Волгоградского государственного университета, ул. 40 лет Победы, 11, 404133 г. Волжский, Российская Федерация, egorov@vgi.volsu.ru. 